\title{
O USO DE SONDAS CULTURAIS NO PROCESSO DE DESIGN DE PRODUTO: uma experiência com estudantes de graduação
}

Cláudia Regina Hasegawa Zacar (claudiahzacar@gmail.com)

Universidade Federal do Paraná

Resumo: Este artigo tem por objetivo descrever o processo de desenvolvimento, aplicação e análise de sondas culturais por uma turma de graduação, como etapa do processo de design de produto. Em síntese, as sondas culturais se caracterizam como uma técnica exploratória para investigar fenômenos do cotidiano. Esta abordagem tem como base a autodocumentação, que é realizada pelos participantes a partir de objetos e tarefas projetados para este fim. Os resultados obtidos por meio dessa técnica podem auxiliar na busca por ideias e inspirações para projetos de design. O processo de desenvolvimento das sondas aqui descrito foi realizado em três etapas principais, adaptadas da metodologia proposta por Mattelmäki (2006): 1) sintonização; 2) projeto das sondas e; 3) interpretação e resultados. Posteriormente foram geradas alternativas e desenvolvidas soluções para os problemas identificados a partir da sondagem. Algumas dessas soluções são aqui apresentadas para ilustrar o processo realizado. Por fim, são elencados e discutidos os principais pontos positivos e negativos dessa experiência, considerando os resultados obtidos e a metodologia utilizada.

Palavras-chave: design de produto, metodologia, sondas culturais.

Abstract: This paper aims to describe the process of development, implementation and analysis of cultural probes by a group of graduate students, considering probes as phase of the product design process. In summary, cultural probes are characterized as an exploratory technique for investigating everyday events. This approach is based on selfdocumentation, which is performed by participants through objects and tasks designed for this purpose. The results obtained with this technique can assist in the search for ideas and inspiration for design projects. The development process of the probes here described was performed in three main steps, adapted from the methodology proposed by Mattelmäki (2006): 1 ) tuning in; 2 ) designing the probes and ; 3 ) interpretation and results. Later on, alternatives were generated and solutions to the identified problems were developed. Some of these solutions are presented here to illustrate the process. Finally, the major positive and negative aspects of this experience, considering the results obtained and the methodology used, are listed and discussed.

Keywords: product design, methodology, cultural probes. 


\section{INTRODUÇÃO}

Este artigo tem por objetivo descrever o processo de desenvolvimento, aplicação e análise de sondas culturais por uma turma de graduação, como etapa do processo de design de produto. Busca-se ainda discutir os pontos positivos e negativos dessa experiência, considerando os resultados obtidos e a metodologia utilizada.

O trabalho aqui descrito foi desenvolvido como parte da disciplina de Design \& Emoção, que é optativa para os cursos de graduação em Design Gráfico e Design de Produto da Universidade Federal do Paraná. Esta disciplina tem por objetivo estabelecer bases para a compreensão do projeto de produtos com ênfase nos aspectos emocionais, bem como seus desdobramentos. Além disso, visa estimular a produção e aplicação de conhecimento, métodos e ações projetuais sob a perspectiva do Design \& Emoção. Considera-se que as sondas culturais alinham-se a esses objetivos, por se tratar de uma técnica baseada na promoção da empatia entre pesquisadores e pesquisados, na busca por identificar e compreender hábitos, formas de socialização, sentimentos e aspirações das pessoas em seus contextos de vida.

Em síntese, as sondas culturais se caracterizam como uma técnica exploratória para investigar fenômenos do cotidiano. Esta abordagem tem como base a autodocumentação, que é realizada pelos participantes a partir de objetos e tarefas projetados para este fim. Os resultados obtidos por meio dessa técnica podem auxiliar na busca por ideias e inspirações para projetos de design.

O processo de desenvolvimento das sondas foi realizado em três etapas principais, adaptadas da metodologia proposta por Mattelmäki (2006): 1) sintonização; 2) projeto das sondas e; 3 ) interpretação e resultados. Posteriormente foram geradas alternativas e desenvolvidas soluções para os problemas identificados a partir da sondagem. O tema geral do trabalho foi a saúde de estudantes universitários. Desta forma, o subtítulo do artigo possui, intencionalmente, uma dupla interpretação: diz respeito à experiência vivida pelos estudantes que cursaram a disciplina e desenvolveram as sondas, mas também considera os estudantes que participaram da sondagem, revelando aspectos do seu cotidiano.

Nas próximas seções, procura-se expor, em linhas gerais, a técnica das sondas culturais, bem como descrever em detalhes a metodologia empregada na experiência que serviu como base para este artigo. Na sequência, são apresentados alguns resultados obtidos, e são discutidas, ao final, as principais vantagens e desvantagens observadas ao longo do processo.

\section{SONDAS CULTURAIS}

As sondas culturais constituem-se como uma abordagem interpretativa, que faz uso de objetos projetados e tarefas provocativas que servem para dar suporte à inclusão dos futuros usuários nas etapas iniciais do processo de design (BOEHNER et. al., 2007).

Esta abordagem foi introduzida nos anos 1990, por um grupo de pesquisadores do departamento de Design Interactions, do Royal College of Art (Inglaterra), em um projeto para explorar como melhor integrar os idosos no cotidiano de suas comunidades (BOEHNER et. al., 2007; LEE; BICHARD; COLEMAN, 2008).

As sondas têm como principais características: 1) são baseadas na participação do futuro usuário, por meio de autodocumentação; 2) ocupam-se das percepções e do contexto pessoal do cada participante e; 3) têm um caráter exploratório. A sondagem 
tem como objetivo convidar e/ou provocar os participantes a refletir sobre e verbalizar suas experiências, sentimentos e atitudes, e para visualizar suas ações e contextos (MATTELMÄKI, 2006; JUDICE; JUDICE, 2007a). Devido a seu caráter lúdico e provocativo, pode permitir acesso à questões íntimas, pessoais e idiossincráticas (BOEHNER et. al., 2007).

As atividades das sondas são tipicamente focadas na descrição dos contextos e práticas atuais, bem como na exploração de oportunidade de design para o futuro (LUCERO et. al., 2007). Em geral, são utilizados kits com câmeras fotográficas, diários, cartões postais, mapas, entre outros, contendo orientações gerais e questões abertas e evocativas, para incitar a reflexão dos participantes (BOEHNER et. al., 2007). Os participantes completam os materiais e os retornam aos pesquisadores para interpretação. O conteúdo dos kits pode ser alterado de acordo com o projeto, sempre tendo como foco o estímulo aos participantes, visando capturar suas experiências ao longo da realização das atividades propostas nas sondas (LUCERO et. al., 2007).

Mattelmäki (2006) aponta quatro razões para a aplicação de sondas culturais em estágios inicias do processo de design: 1) para coleta de informações; 2) para ampliar a inspiração; 3) para facilitar o diálogo entre usuários e designers e entre a equipe de projeto e; 4) para aumentar a participação do usuário na criação de soluções de design, ao permitir que eles expressem suas ideias e necessidades.

Assim, as sondas podem ser utilizadas para uma coleta inicial de dados, auxiliando na definição de requisitos projetuais e eventualmente complementando abordagens etnográficas, na busca pela compreensão de um contexto específico (BOEHNER et. al., 2007).

O processo de sondagem cria possibilidade de interação e diálogos com os participantes. As sondas podem facilitar a criação de laços de confiança entre os pesquisadores e os participantes. Podem motivar os participantes a dividir detalhes sobre suas vidas, sonhos e sentimentos. Além disso, as informações servem como base para o processo de relacionar as ideias com as experiências dos próprios pesquisadores, promovendo um entendimento empático (GAVER et. al., 2004).

É válido ressaltar que a aplicação das sondas não dá origem a soluções únicas e perfeitas, mas elas geralmente fornecem uma ampla gama de ideias potenciais, que podem levar a muitas soluções possíveis (LUCERO et. al., 2007). Além disso, as sondas não foram concebidas como uma técnica "científica" e, portanto, Gaver et. al. (2004) não recomendam seu uso de forma excessivamente controlada (por meio de uma amostragem rigorosa ou análise estatística dos dados, por exemplo). Para os autores, esse tipo de aplicação coloca em risco os principais benefícios e potenciais aprendizados que podem decorrer do uso das sondas culturais.

Ainda assim, a técnica tem se mostrado satisfatória em diversas pesquisas de cunho acadêmico, inclusive no Brasil. Como exemplos, é possível citar dois trabalhos desenvolvidos junto a populações de baixa renda. Judice e Judice (2007a, 2007b), por exemplo, utilizaram sondas culturais em uma pesquisa voltada ao desenvolvimento de sistemas de informação para melhorar a saúde de comunidades do Rio de Janeiro. Já Daros (2013), ilustra a utilização de sondas culturais para identificar hábitos de consumo de água e energia em habitações de interesse social da região de Curitiba.

No curso de graduação em que foi desenvolvido o processo aqui descrito, a técnica das sondas culturais era pouco conhecida e praticamente não aplicada em 
projetos. Desta forma, tratou-se se um esforço inicial e de experimentação da técnica, de acordo com a metodologia descrita na próxima seção.

\section{METOdologia de DESENVOLVIMENTO, APLICAÇÃO E ANÁlISE DAS SONDAS CULTURAIS}

Conforme já citado, o trabalho aqui descrito foi desenvolvido como parte da disciplina de Design \& Emoção, que possui carga horária total de 30 horas e é optativa para os cursos de graduação em Design Gráfico e Design de Produto da Universidade Federal do Paraná. O trabalho teve duração total de seis semanas, com encontros semanais de duas horas para acompanhamento e orientação.

As atividades aqui descritas referem-se à turma que cursou a disciplina no primeiro semestre do ano de 2013. No total, participaram vinte e nove estudantes, sendo vinte e três do curso de Design de Produto e seis do curso de Design Gráfico. $O$ grupo reuniu alunos dos terceiros e quartos anos dos referidos cursos.

A proposta do trabalho tinha como objetivo a concepção de soluções voltadas à melhoria da saúde de estudantes universitários, a partir de informações e insights obtidos por meio de sondas culturais. $O$ trabalho foi desenvolvido em equipes de três ou quatro pessoas e, dadas as características da turma, procurou-se estimular o trabalho conjunto dos estudantes dos dois cursos (Design Gráfico e Design de Produto). Cada grupo ficou livre para identificar um aspecto específico a ser trabalhado dentro da temática geral proposta. Desta forma, foram identificadas pelas diferentes equipes questões como: alimentação, exercícios físicos, estresse, tabagismo e sono.

A metodologia de desenvolvimento do trabalho foi adaptada a partir da proposta de Mattelmäki (2006), que divide o processo em cinco etapas: 1) sintonização; 2) aproximação com o público alvo; 3) projeto das sondas; 4) aprofundamento; 5) interpretação e resultados.

Como salienta a autora, as cinco etapas são adequadas quando se almeja entender a fundo um fenômeno ou contexto, por meio de um processo interativo. Mattelmäki (2006) sugere, porém, que é possível também suprimir a etapa de aprofundamento, em situações em que se busca, primordialmente, utilizar as sondas culturais como fonte de inspiração para projetos. Considerando essa ressalva, e dado o curto tempo disponível na disciplina, procurou-se condensar o desenvolvimento em três etapas principais, conforme descrito a seguir.

Depois de selecionados os temas específicos, partiu-se para a etapa de "sintonização", que acabou mesclando-se com a etapa de "aproximação com o público-alvo", conforme proposto por Mattelmäki (2006). Isto porque o público a ser pesquisado era extremamente próximo à realidade dos estudantes. ${ }^{1}$ Assim, foi utilizado o conhecimento tácito das equipes, além de terem sido realizadas pesquisas na internet, para levantamento de informações adicionais.

Estes dados foram reunidos, analisados e compilados em mapas mentais, que direcionaram a posterior definição dos objetivos a serem alcançados e assuntos a serem abordados por meio das sondas culturais. Considerando o caráter específico da

\footnotetext{
${ }^{1} \mathrm{O}$ direcionamento do trabalho à pesquisa com estudantes universitários foi dado justamente para facilitar, nesta primeira experiência, o desenvolvimento das sondas e a interpretação dos resultados. 0 aspecto específico da saúde foi selecionado considerando notícias veiculadas em jornal local, que indicaram problemas como o excesso de consumo de álcool e a má alimentação entre os estudantes ver, por exemplo, Simas (2012) e Lima (2012).
} 
disciplina, procurou-se estimular a atenção às questões relacionadas às experiências do público pesquisado, com enfoque especial nos aspectos afetivos. Esta primeira etapa foi toda desenvolvida em um único dia letivo.

$\mathrm{Na}$ sequência, iniciou-se a segunda etapa do processo, a de "projeto das sondas". Esta etapa teve início com discussões a partir dos dados sintetizados na fase anterior. Assim, cada equipe refletiu sobre as propriedades possíveis para os objetos e tarefas a serem propostos, considerando os objetivos almejados e os assuntos a serem abordados. Foram realizadas sessões de brainstorming para a geração de ideias. A partir de uma avaliação, levando em conta o contexto de aplicação das sondas e sua efetividade, cada equipe selecionou os materiais e estratégias a serem posteriormente desenvolvidos. Foi solicitado que cada equipe selecionasse pelo menos três materiais diferentes para compor o kit das sondas culturais.

O próximo passo, ainda nesta etapa, foi a materialização das sondas. Neste momento, enfatizou-se a necessidade de elaborar materiais atrativos, que motivassem os participantes a completar as tarefas e a coletar os dados por meio das sondas. Foram discutidas também questões relacionadas ao entendimento das tarefas propostas e da praticidade da coleta dos dados por parte dos pesquisados. As equipes tiveram, no total, três semanas para a concepção e elaboração dos kits.

Depois de preparados os materiais, as sondas culturais foram finalmente entregues aos participantes. Estipulou-se que seriam entregues, por equipe, de três a seis sondas no total. Esta limitação foi imposta visando minimizar o grau de complexidade da posterior análise do material, dado o pouco tempo disponível. Cada equipe ficou responsável por identificar e abordar potenciais participantes. Diversas estratégias foram utilizadas para tanto: alguns optaram por incluir pessoas próximas aos seus círculos de amizade, outros abordaram diretamente pessoas desconhecidas no campus da Universidade.

Após a seleção e anuência dos participantes, as sondas foram entregues. Neste momento, o objetivo da pesquisa e as atividades a serem realizadas foram explicadas pelas equipes aos participantes.

Em geral, não há uma indicação precisa em relação ao tempo para a coleta de dados - este período varia de acordo com a natureza dos fenômenos que se deseja observar, do tipo de contexto, das características dos participantes, entre outros, podendo variar de alguns dias a várias semanas. No caso do processo aqui relatado, cada participante permaneceu, em média, sete dias com o material das sondas. Este período foi sugerido como padrão, considerando que seria importante observar as possíveis mudanças de hábitos ocorridas entre os dias úteis e o final de semana.

Após o período estipulado, as equipes recolheram as sondas e fizeram uma análise preliminar do material, que consistiu basicamente na leitura daquilo que tinha sido registrado pelos participantes e em uma preliminar observação de possíveis padrões, respostas difíceis de compreender, informações inesperadas, dados significativos, etc. Na sequência, essas primeiras leituras e impressões foram compartilhadas com as demais equipes, em sala. Este procedimento foi adotado considerando que, pelo fato de todos estarem trabalhando com um público similar, a discussão assim ampliada poderia ser mais produtiva na interpretação dos resultados. Depois disso, equipes voltaram a trabalhar separadamente, visando uma discussão mais aprofundada em relação aos seus temas específicos. 
A interpretação feita por cada equipe serviu de inspiração para a segunda parte do trabalho, que envolveu a concepção e o desenvolvimento de soluções para problemas identificados a partir dos contextos pesquisados. De acordo com o previamente exposto, essa interpretação foi de cunho subjetivo, não tendo sido utilizados procedimentos específicos.

Para a geração de alternativas foi utilizadas a técnica de brainstorming. Depois disso, as equipes selecionaram uma das alternativas para posterior desenvolvimento. Esta seleção foi feita com base na percepção, construída a partir dos resultados das sondas, acerca do contexto do público pesquisado. Dado o curto espaço de tempo e o caráter da disciplina, não foi exigido que se levassem em conta critérios como viabilidade técnica e econômica, mas que se buscasse selecionar aquelas ideias com maior potencial de instigar, afetar e promover mudanças no cotidiano do público pesquisado.

As ideias selecionadas foram posteriormente elaboradas, para então serem apresentadas aos colegas e à professora. O desenvolvimento e finalização das soluções propostas ocorreram em duas semanas. A apresentação englobou todo o processo de desenvolvimento das sondas e das soluções propostas. Ao final das apresentações, foi realizada uma discussão com a turma, considerando pontos positivos e negativos do trabalho realizado, conforme será exposto na última seção deste artigo.

\section{EXEMPLOS DE TRABALHOS DESENVOLVIDOS}

A partir das etapas descritas, foram desenvolvidas, no total, nove sondas culturais, que resultaram em nove soluções diferentes. Serão aqui ilustrados em maior detalhe apenas dois dos trabalhos.

O primeiro deles teve como objetivo analisar a questão do sono dos estudantes universitários, procurando mapear os períodos anterior e posterior ao dormir. Neste sentido, a equipe buscou identificar os hábitos associados a estes momentos, incluindo os locais e horários em que os participantes dormiam, bem como as dificuldades e sensações associadas ao sono. Para tanto, distribuíram as sondas para três jovens universitários, estudantes de Design, com idades entre 21 e 26 anos. Os materiais das sondas (figura 1) incluíram:

1) uma fronha acompanhada de caneta própria para tecido: nesta, os participantes eram convidados a escrever ou desenhar como se sentiam antes de dormir e na hora de acordar.

2) um cubo com questões gerais relacionadas ao sono: nele os participantes deveriam registrar quantas horas gostariam de dormir, os motivos que eventualmente os faziam dormir menos ou pior do que gostariam, as atividades realizadas antes de dormir, entre outras.

3) fichas: nelas, os participantes deveriam preencher os horários em que foram dormir e em que acordaram, onde dormiram e com quem. As fichas eram posteriormente depositadas no interior do cubo acima descrito. 


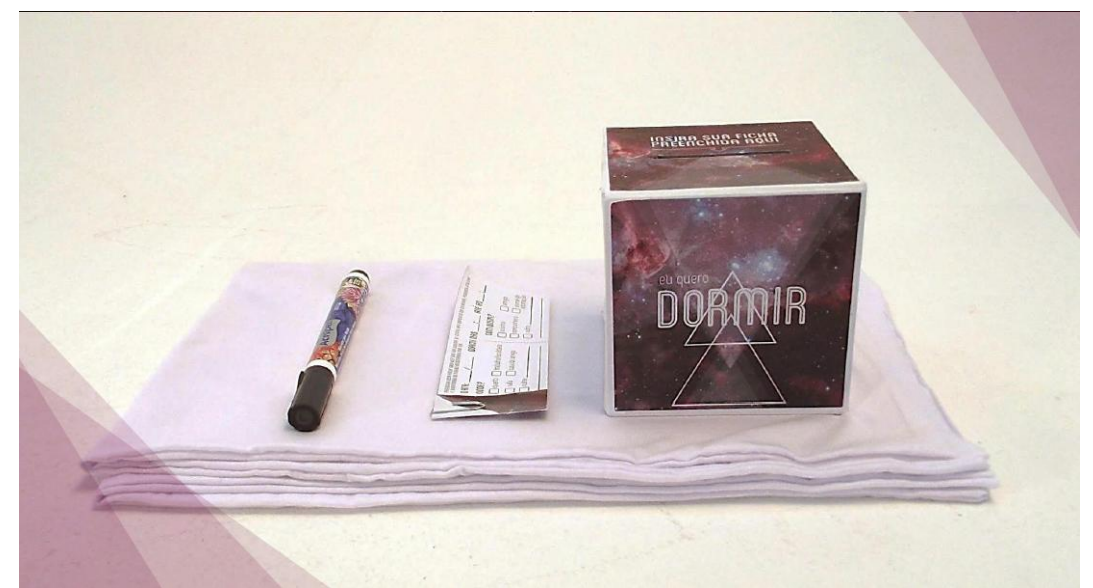

Figura 1 - Materiais das sondas culturais (tema: sono)

Fonte: BATTINI; IWAMOTO; ORSO, 2013

A partir das informações coletadas por meio dos materiais desenvolvidos (figura 2), a equipe identificou que, diferentemente das hipóteses iniciais (de que o mais difícil para os participantes seria o momento de acordar), era crítico o processo de relaxamento anterior ao sono. Os participantes demoravam para relaxar depois de dias agitados, e tinham o hábito de realizar diferentes atividades antes de dormir. A partir dessa constatação, a equipe desenvolveu uma almofada voltada a auxiliar no relaxamento (figura 3). Esta seria dotada de um mecanismo vibratório que emitiria ondas similares às do ronronar dos gatos. Esta estratégia foi selecionada utilizando como referência uma pesquisa que indicava que a frequência do ronronar auxilia no relaxamento das pessoas.

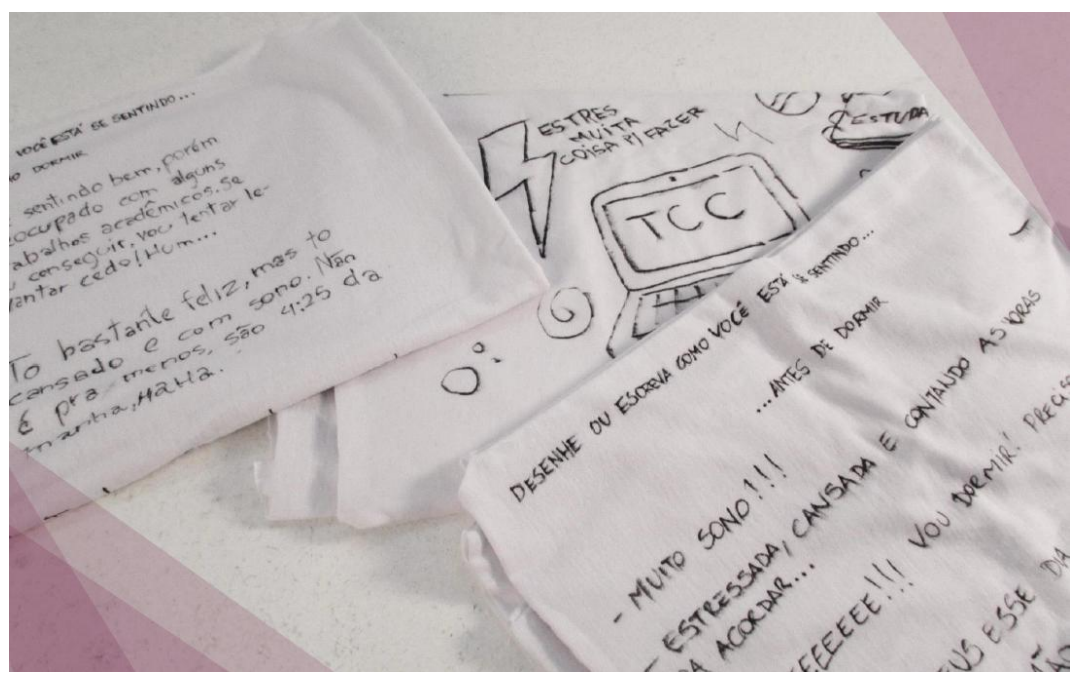

Figura 2 - Parte dos resultados obtidos com as sondas culturais (tema: sono)

Fonte: BATTINI; IWAMOTO; ORSO, 2013 


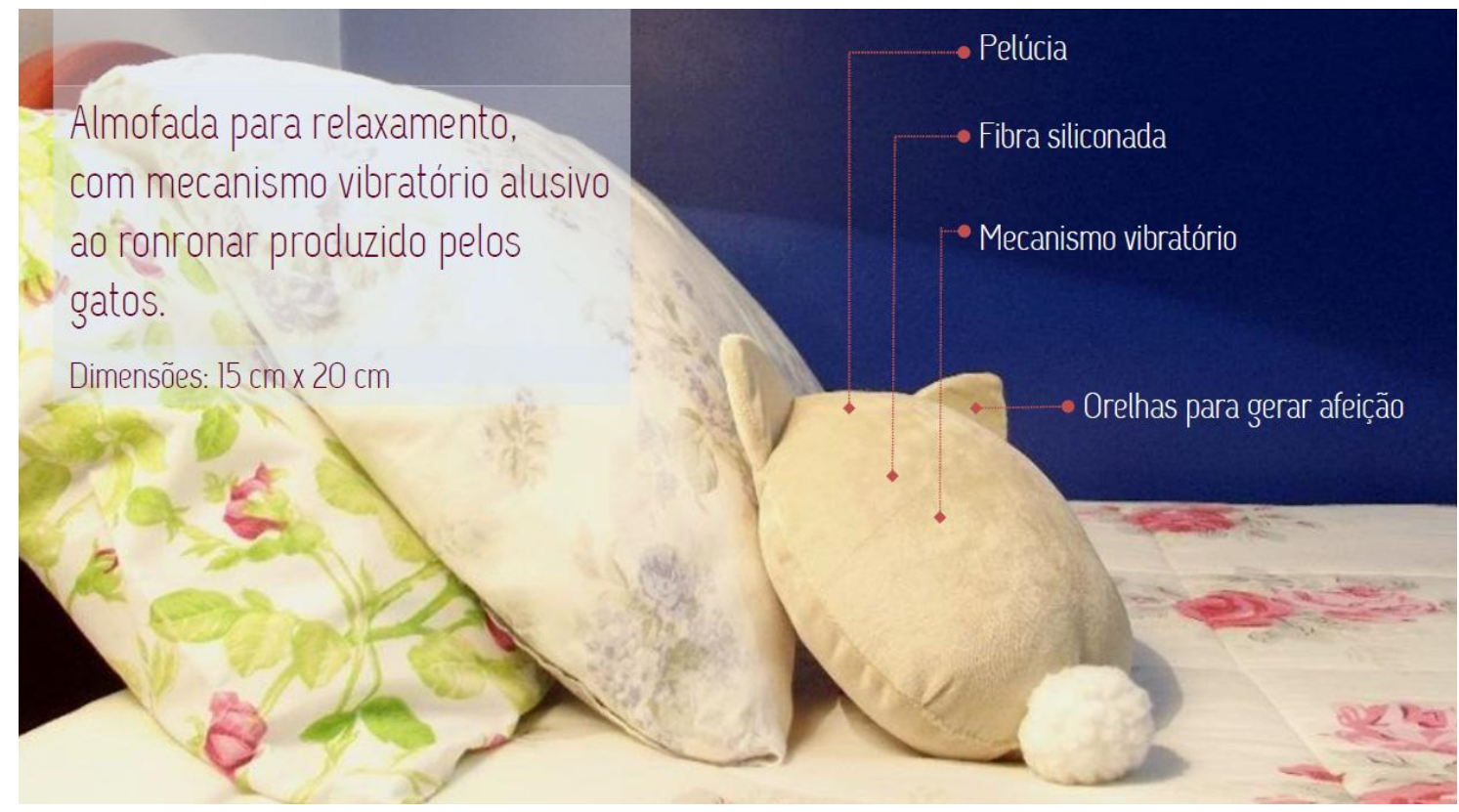

Figura 3 -Solução proposta (tema: sono)

Fonte: BATTINI; IWAMOTO; ORSO, 2013

O segundo trabalho a ser aqui descrito teve como objetivo abordar a questão da alimentação dos estudantes universitários. A equipe buscou analisar aspectos gerais relacionados a esta prática, como: o que os participantes comiam, em quanto tempo, quanto gastavam com a alimentação, e qual a percepção em relação à qualidade dos alimentos consumidos e ao grau de satisfação obtido. Foram distribuídas três sondas, para estudantes universitários com perfis alimentares diversos ("saudável", "pouco saudável" e "vegetariano").

Neste caso, as sondas utilizaram recursos alinhados à ideia de mobile probes ("sondas móveis"), conforme citado por Mattelmäki (2006). Este tipo de sonda se baseia no uso de dispositivos como os smarphones, telefones celulares com câmeras fotográficas e acesso à internet. Assim, os participantes foram estimulados a tirar fotografias de suas refeições e enviá-las à equipe, bem como utilizar o cronômetro dos celulares para marcar o tempo gasto em cada refeição. Além disso, os participantes receberam diários para registro de horários, gastos e percepções relacionadas à sua alimentação. Para facilitar o preenchimento, os diários vinham acompanhados de adesivos indicativos (saudável/ não saudável, saboroso/ pouco saboroso, satisfatório/ pouco satisfatório, caro/barato) (figura 4).

Um problema identificado em relação a todos os participantes, independentemente de seu perfil alimentar, foi o pouco tempo gasto em cada refeição. Um deles chegou a fazer uma refeição em apenas três minutos. Isto levou a equipe a desenvolver uma solução voltada a "educar" o público a comer mais devagar.

O produto proposto é um prato (figura 5) dotado de um mostrador que indicaria o peso da comida nele depositada e o tempo de consumo sugerido para aquela quantidade. $\mathrm{Na}$ base do prato haveria um sensor de peso. Caso o volume de comida se esvaziasse no tempo sugerido (e não menor que este), seria indicada no mostrador uma senha, que o usuário utilizaria para destravar um recipiente em que estaria contida a sobremesa. Assim, além de facilitar a percepção do tempo decorrido 
em cada refeição, o sistema estimularia o usuário a comer mais devagar, com o intuito de ganhar uma recompensa (a sobremesa).

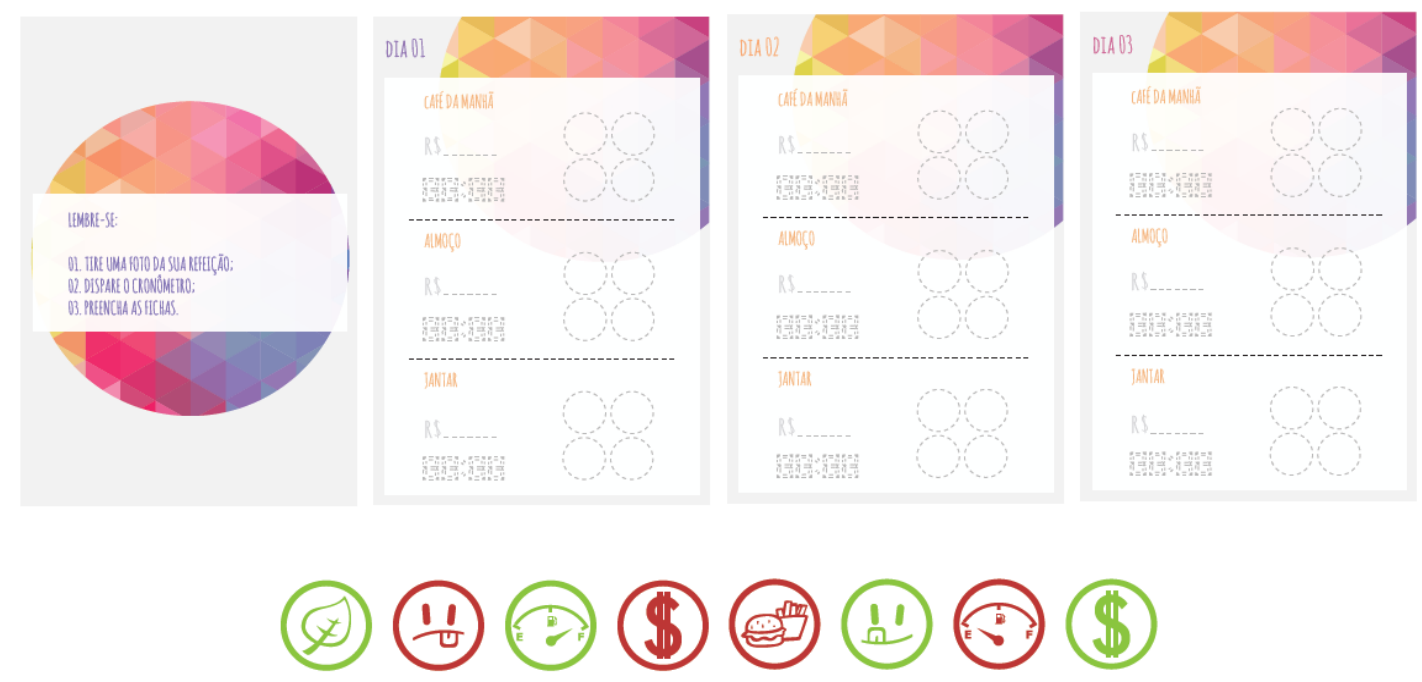

Figura 4 - Materiais das sondas culturais (tema: alimentação)

Fonte: HAHNER; PIMENTEL; SHOYAMA; TRIAQUIM, 2013

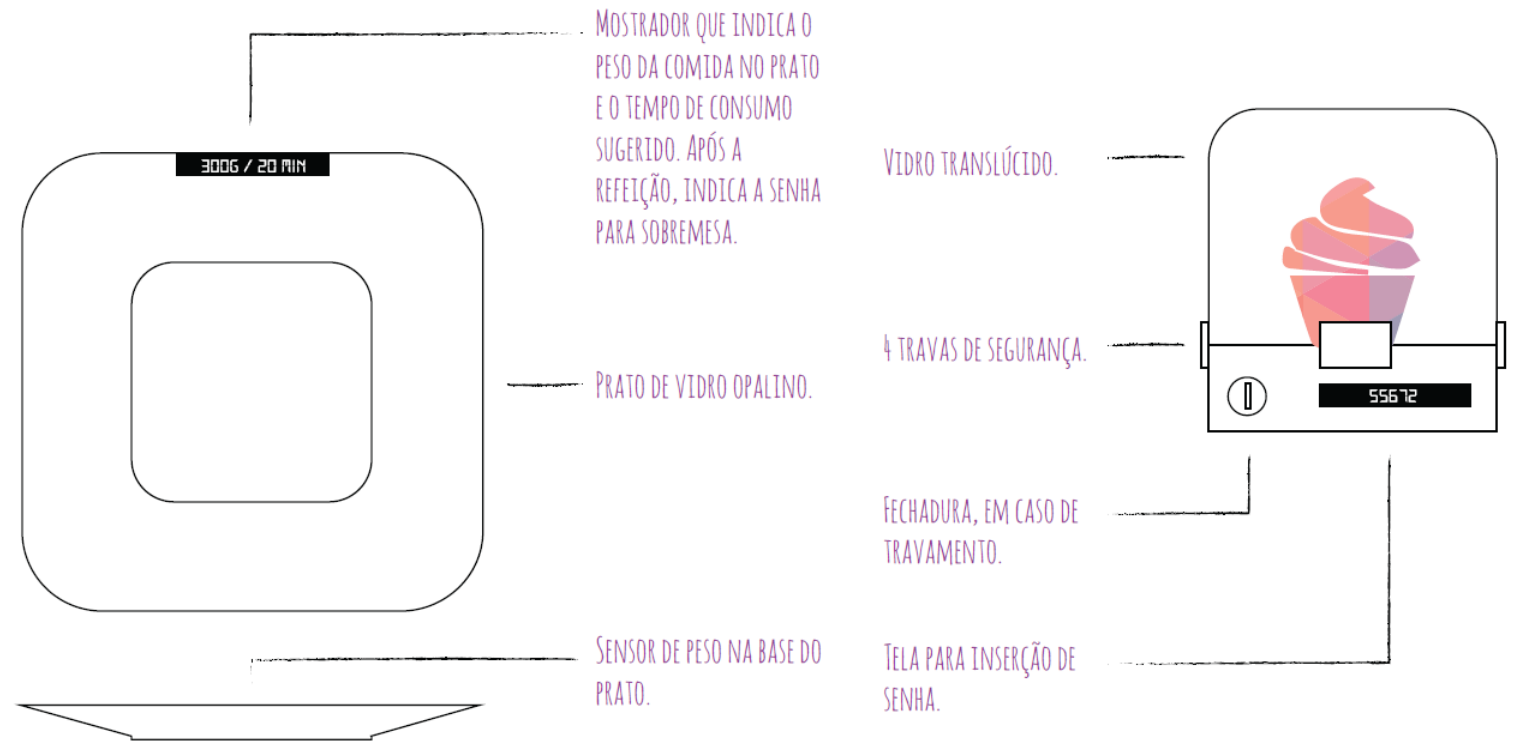

Figura 5 - Solução proposta (tema: alimentação)

Fonte: HAHNER; PIMENTEL; SHOYAMA; TRIAQUIM, 2013

Além desses dois exemplos, foram desenvolvidas pela turma outras soluções, como: um aplicativo para avaliar colegas e facilitar a escolha de equipes para a realização de trabalhos, visando reduzir o estresse; um sistema de gerenciamento das atividades acadêmicas diárias, para otimizar o uso do tempo; uma instalação para estimular a prática de exercícios físicos na universidade; um chuveiro com estímulos sensoriais, para ajudar a relaxar ou a despertar; uma garrafa de fácil transporte para incentivar o consumo de água; um aplicativo para facilitar a formação de grupos para a prática de esportes coletivos. 


\section{CONSIDERAÇÕES FINAIS}

Considera-se que, de maneira geral, os resultados obtidos a partir da experiência aqui descrita foram bastante positivos. Os alunos envolvidos na elaboração das sondas consideraram o processo interessante e prazeroso, apesar de trabalhoso. Os estudantes que completaram as sondas também se interessaram pelo material, e cumpriram a grande maioria das tarefas propostas.

Algumas respostas obtidas foram bastante tocantes, abrangendo questões delicadas ${ }^{2}$ das histórias de vida dos participantes. Desta forma, pode-se considerar que as sondas de fato contribuíram para o estabelecimento de uma maior confiança dos participantes nos pesquisadores, e promoveram uma maior empatia entre ambos os grupos. Além disso, o processo de design resultou em soluções criativas e instigantes, a partir dos insights obtidos.

Notou-se, porém, um certo "acanhamento" por parte das equipes, que não ousaram muito em relação aos tipos de objetos e tarefas propostos nas sondas. A grande maioria, por exemplo, utilizou como principal instrumento o diário, já tradicionalmente usado neste tipo de abordagem. Foi comum, também, o uso de questões e tarefas mais fechadas, específicas e direcionadas, o que, para Gaver et. al. (2004) tende a levar a resultados mais limitados. Salienta-se, portanto, a necessidade de estimular a elaboração de tarefas mais abertas e até absurdas, visando obter informações potencialmente mais surpreendentes (GAVER et. al., 2004). Neste sentido, sugere-se ser interessante o desenvolvimento ou adaptação de técnicas de criatividade para este fim.

Ainda com relação a esta dificuldade, considera-se que o foco específico em determinados aspectos da vida dos participantes (como sono, alimentação, estresse), pode ter influenciado nesse excessivo direcionamento. Sugere-se, para experiências futuras, realizar sondagens mais gerais sobre o cotidiano, hábitos, expectativas e sentimentos das pessoas. Dessa forma, as oportunidades para o design tenderão a abranger campos mais diversos, a partir de uma compreensão mais ampla sobre o contexto de vida das pessoas.

Provavelmente esse redirecionamento exigiria um tempo maior para elaboração e análise dos resultados das sondas. Em relação à etapa de análise, acredita-se que esse redirecionamento também tornaria mais produtiva a etapa de compartilhamento das informações e impressões entre as equipes que, da forma com que foi conduzida nessa primeira experiência, não se mostrou muito útil, uma vez que houve pouco debate e efetiva troca entre os grupos.

Por fim, recomenda-se a aplicação mais ampla da técnica de sondas culturais como etapa inicial no processo de design de produto, notadamente nos projetos propostos para turmas de graduação. Acredita-se que esta abordagem contribui para sensibilização dos designers com relação às pessoas para quem projetam, aumentando a empatia e facilitando o posterior desenvolvimento de produtos que sejam de fato significativos para elas.

\footnotetext{
${ }^{2}$ Um dos participantes da sondagem sobre tabagismo, por exemplo, forneceu informações bastante detalhadas sobre sua condição de ex-usuário de drogas.
} 


\section{REFERÊNCIAS}

BOEHNER, Kirsten et. al. How HCl Interprets the Probes. Anais... CHI 2007 Designing for Specific Cultures. San Jose, CA, USA, abr./maio, 2007.

DAROS, Carolina. Design para a sustentabilidade: oportunidades de inovação a partir dos hábitos de consumo na habitação de interesse social. 2013. Dissertação (Mestrado em Design), Programa de Pós Graduação em Design, Universidade Federal do Paraná. Curitiba, 2013.

GAVER, William et. al. Cultural Probes and the value of uncertainty. Interactions, v. XI.5, p. 53-56, 2004.

JUDICE, Andrea; JUDICE, Marcelo. (2007a). Designing cultural probes to study "invisible" communities in Brazil. Design Inquiries, 2007.

JUDICE, Andrea; JUDICE, Marcelo (2007b). Empathy Probes in Brazil: "Faith, Trust and Pixie Dust!". 2007. Disponível na internet por http em: < http://tm.uiah.fi/tutpor/AOR2 007/ Judice.pdf>. Acesso em 9 abril 2010.

LEE, Yanki; BICHARD, Jo-Anne; COLEMAN, Roger. Designing with users, how? Investigate users involvement tactics for effective inclusive design processes. Anais... INTERNATIONAL DMI EDUCATION CONFERENCE. Design Thinking: New Challenges for Designers, Managers and Organizations. Cergy-Pointoise, França, abril 2008.

LIMA, Jônatas Dias. Beber até cair é comum entre jovens: pesquisas recentes constatam que acadêmicos exageram na bebida. Proximidade entre bares e câmpus incentiva o consumo. Gazeta do Povo, Curitiba, 26 nov. 2012. Disponível na internet por http em: <http://www.gazetadopovo.com.br/vida-universidade/conteudo.phtml?i

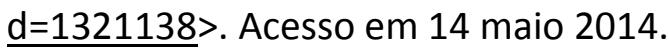

LUCERO, Andrés et. al. How Probes Inform and Influence the Design Process. Anais... DESIGNING PLEASURABLE PRODUCTS AND INTERFACES. Helsinki, ago. 2007.

MATTELMÄKI, Tuuli. Design Probes. Vaajakoski: University of Art and Design Helsinki, 2006.

SIMAS, Anna. Sozinhos e mal alimentados: macarrão instantâneo e congelados são os alimentos mais consumidos por universitários que vivem longe dos pais. Gazeta do Povo, Curitiba, 12 nov. 2012. Disponível na internet por http em: <http://www.gazetadopovo.com.br/vida-universidade/conteudo.phtml?tl=1\&id=1316 732\&tit=Sozinhos-e-mal-alimentados $>$. Acesso em 14 maio 2014. 